\title{
HUMANIDADES Y EDUCACIÓN: OCULTAMIENTO CURRICULAR
}

\author{
José Alberto de la Fuente \\ Universidad Cardenal Silva Henríquez - USACH
}

\section{UN PROYECTO ABORTADO}

La sociedad chilena, entre 1910 y 1938, se dio un espacio para reflexionar y decidir la importancia de la educación primaria con carácter de pública y obligatoria para todos los niños chilenos. El presidente Pedro Aguirre Cerda intuyó que su tiempo de gobernanza perduraría en la memoria a través del lema "Gobernar es educar". Esta nueva concepción de ejercer el poder, sin duda que para la época fue un signo de proyección cultural relevante en un país con débil sustentación democrática; un país que aspiraba a construir una república autónoma y con una amplia y plural participación ciudadana. Los intereses populares representados por gremios, mancomunales obreras, sindicatos, sociedades de artesanos, empresarios con sensibilidad social, partidos políticos, universidades, escritores, artistas, intelectuales, estudiantes y trabajadores del campo y la ciudad, emprendieron sus acciones con perseverancia cívica hasta consolidar la idea de un Estado Docente, cuya meta era educación nacional, igualitaria e inclusiva. La década de los 60 marca un antes y un después en el proceso por seguir avanzando en nuevas políticas educativas y culturales, en ampliar la cobertura de matrícula en la educación gratuita y desarrollar políticas que accedieran a la lectura (Editorial Quimantú), especialmente en los hogares y jóvenes más necesitados.

A partir de 1973, se jibariza en todas sus metas el Estado Docente. El acontecer político habido en Chile desde 1973 hasta 1989 clausura la conciencia crítica del mundo académico, interviene el claustro universitario, desnaturalizando la autonomía y municipalizando la administración del sistema 
primario y secundario. Posteriormente, las cegueras políticas y culturales, los conflictos de intereses excluyentes y la incapacidad de consenso de los diversos actores involucrados en el devenir de nuestro sistema educacional han ido marcando retrocesos, negaciones y debilidades incuestionables en todos los niveles. Un breve balance sobre lo acontecido nos indica que las ideas y esfuerzos por una mejor e innovadora educación respondían a una concepción humanista y democrática. En los últimos cuarenta años, el Estado hace un abandono de su responsabilidad en educación; la educación deja de ser un derecho humano o un bien universal, sustituido por la idea de que se trata de un simple "bien de consumo" regulado por la oferta y la demanda. Los resultados están a la vista: en la actualidad, Chile es el país de la OCDE con los peores índices en logros escolares en casi todos sus niveles.

\section{EL ÁREA DE LENGUAJE Y COMUNICACIÓN}

El propósito de este trabajo es ilustrar con evidencias y variables curriculares lo acontecido en el área de Lenguaje y Comunicación centrada en el subsector curricular de Lengua Castellana y Comunicación, tal como opera hoy en día. Las leyes y decretos reguladores que se encargaron de ir ocultando, sustituyendo y desviando la formación humanista en la Educación Básica y Media, aún están vigentes y otras han sido readecuadas, pero no cambiadas en su espíritu. Se trata de la Ley Orgánica Constitucional de Educación $\mathrm{N}^{\circ}$ 187.962 (LOCE), promulgada por la dictadura en 1990; los Decretos 40/96 y 220/98 y sus modificaciones a los marcos curriculares vigentes (Objetivos fundamentales y Contenidos mínimos obligatorios para Básica y Media); y de la Ley General de Educación N²0.370, promulgada el 12 de septiembre de 2009 (LGE); y el 5 de julio de 2011, el Gran Acuerdo Nacional por la Educación (GANE), fallido intento del gobierno por revertir el alcance y sentido de las demandas del magisterio y de los estudiantes. Con estas leyes va desapareciendo del currículo la asignatura de Castellano o Español como enseñanza-aprendizaje de un idioma y de la literatura en su tradición estético-humanista, siendo sustituida por el híbrido epistémico de Lenguaje y Comunicación que trastoca su rango artístico por un reduccionismo utilitario.

Aprovechándose de la libertad para hacer adaptaciones sectoriales a los programas, los rectores y directores de colegios de mayores recursos mantienen el nombre de Lengua Castellana y Comunicación; sin embargo, ante la nueva ideología que ya no distingue los discursos propiamente literarios de textos 
narrativos destinados a la pragmática de la comunicación, se desdibujan los géneros, los estilos y recursos específicos de la creación literaria, propios de una formación estética y humanista. La palabra ha sido desplazada por la imagen; la literatura pareciera estar condenada a la obsolescencia, ajena a los referentes de realidad que se cristalizan en ella. La lectura ocupa un lugar secundario; domina el comentario periodístico, el tacto digital y el silencio de la cibernética como recursos preferentes para comprender y explicar el mundo. Esta sustitución se naturaliza, como veremos en los textos de estudio ministeriales y en la concepción mercantil de la educación.

\section{DESACOPLE ESTRUCTURAL}

En adelante, entenderemos por desacople estructural el desajuste, desarticulación y falta de coherencia entre las orientaciones ministeriales generales, los textos de estudio y las orientaciones ministeriales destinadas a cooperar para el éxito y práctica efectiva del proceso enseñanza-aprendizaje. Entre estos factores concomitantes, los más importantes y evidentes son la filosofía educacional que se traduce en políticas y opciones ideológicas, el currículo para la formación de profesores, el liderazgo y la organización interna de las escuelas y liceos (que es exageradamente normativa en detrimento de la participación), los procesos de evaluación de los aprendizajes, las rúbricas, los textos de estudio de los alumnos de Básica y Media ${ }^{1}$ y las falacias teóricas que aparecen en los textos y que pretenden normar el discurso literario de los profesores.

Las zonas ocultas del currículo en Básica y Media omiten o reducen a su mínima expresión la relevancia de la literatura, el valor de la palabra, las ciencias sociales, la importancia de las artes y la filosofía para el desarrollo del pensamiento situado y de la conciencia crítica, etc. Se oculta la posibilidad de "pensar por cuenta propia", es decir, de observar críticamente nuestra realidad para reflexionar a la luz de nuestra idiosincrasia, procesos políticos, autonomía, identidad y participación ciudadana. Este ocultamiento no es fortuito ni es por azar; pienso que esta actitud está respaldada por una visión de mundo excluyente, hegemónica y de pensamiento único que desconoce

Más adelante incluimos los textos de estudio revisados y vigentes que, aleatoriamente, y aún de manera restringida, han servido de base para demostrar uno de los factores determinantes del desacople estructural. 
la diversidad y el derecho a analizar la experiencia desde distintos ángulos para discutir y recuperar democráticamente el sentido de pertenencia a una nación y a un continente; a todo lo cual debe apuntar una buena formación en humanidades. Este fenómeno sociocultural se refrenda hoy día en la crisis aguda del actual modelo pedagógico y didáctico, especialmente en las escuelas y liceos de los sectores más pobres y carenciados, también se expresa en la censura ministerial a los textos de estudio de Historia de Chile, a la reducción de horas en el área de filosofía y en la fragmentación de las obras literarias incluidas en esos mismos textos. Queda en evidencia que las zonas ocultas del currículo son la expresión de aquellas contradicciones teóricas y prácticas, entre las declaraciones del Ministerio de Educación sobre innovaciones de forma que ha pretendido realizar y lo que acontece efectivamente con sus aplicaciones, instructivos pedagógicos y didácticos en aulas, talleres, aprendizaje en terreno y textos de estudios licitados y promovidos por el propio Ministerio. Por su parte, la administración municipal de la educación no ha sido capaz de responder a los resguardos académicos y de formación integral, tanto de alumnos como de maestros, con el propósito de asomarse a los desafíos de un tipo de sociedad globalizada que cada día es más exigente en términos de conocimiento e información.

\section{PROFESORES Y EJERCICIO DOCENTE}

En cuanto a la formación de profesores, se van extinguiendo los núcleos epistémicos de la Pedagogía en Castellano para reemplazarla, por la indefinida área curricular de Lenguaje y Comunicación, con un fuerte componente periodístico, dosificaciones pseudo-sociológicas y escasa correspondencia entre el desempeño profesional y el rol de los profesores para interactuar como sujetos sociales ¿Por qué se ha ido prescribiendo el currículo humanísticocientífico para la formación de profesores bajo tecnicismos que eluden la importancia de incorporar dimensiones antropológicas que integren las ciencias humanas, opciones filosóficas y valores sobre el tipo de hombre y mujer que se quiere formar? ¿Cómo se entiende y qué función le atribuye la Ley $\mathrm{N}^{\circ} 20.370$ (LGE) a los conceptos clave de la estructura curricular en Lectura, Escritura y Comunicación oral? ¿Por qué los Mapas de Progreso que intentan describir el crecimiento de las competencias consideradas en la formación y que contribuyen a la observación y evaluación de los aprendizajes, no se aplican también a los textos de estudio, aprobados por 
el Ministerio? El origen del problema y la dificultad para responder a estas preguntas radica, en parte, a mi modo de ver, en la ya aludida negación de una tradición educativa nacional pre 1973, en que la asignatura de Castellano tenía un alto componente estético y humanista. Al cambiarse la perspectiva a base de un pensamiento único, se trastoca la orientación humanista por una utilitaria que apunta a la sobrevivencia económica, lo que tiene como trasfondo el concepto de "Estado subsidiario", un Estado que privilegia la libertad de enseñanza en desmedro del derecho a la educación.

Las nuevas tendencias curriculares de la educación superior en Europa y en los Estados Unidos, también de marcada tendencia utilitarista, se han estado aplicando en Chile sin perspectiva crítica, sin considerar la idiosincrasia y los desiguales niveles de capital cultural de los diversos sectores que ingresan a la escuela. A la idea de "flexibilización o de flexibilidad curricular", se aplicó sin más la opción errónea que sin duda favorece a los alumnos más ricos de las escuelas y clases mejor dotadas, por la de "racionalización de la carga académica y la noción de modularización", que reemplaza al tradicional curso en su unidad evolutiva por el módulo como unidad de instrucción básica, en que se supone que los alumnos pueden adquirir por sí mismos un conjunto de nociones y competencias. Esta idea de modularización es la que condiciona y justifica la profunda distancia y desencuentro entre el currículo y las limitantes didácticas de los textos de estudio, situación que está condicionada por el diseño curricular operativo en el sector Lenguaje y Comunicación.

\section{DISEÑO Y FUNCIONAMIENTO DE LOS TEXTOS DE ESTUDIO}

La propuesta legal que justifica el ajuste curricular de 2009 considera que los textos de estudio son un apoyo al mejoramiento continuo del aprendizaje, intención que está acotada en el concepto siguiente: "Los textos escolares son una importante herramienta para la implementación curricular en la sala de clases, constituyendo un apoyo estratégico para el desarrollo del aprendizaje y son un recurso pedagógico utilizado en diversos espacios educativos, tanto dentro del aula como fuera de ella"2. Curiosamente, esta definición no se

2 Carreño, R.; Santos, D.; Ávila, N.; Filla, M.; Montes, C. Lenguaje y Comunicación, $8^{\circ}$ Básico (incluye guía didáctica al docente). Santiago: Editorial Cal y Canto, 2010, en presentación, página 4 . 
condice con el diseño real que presentan la mayoría de los textos que aprueba $\mathrm{y}$ distribuye el Ministerio de Educación, tal como lo comprobaremos en una muestra de siete textos de estudio de Séptimo Básico a Cuarto año de Enseñanza Media, textos que actualmente constituyen lecturas obligatorias y casi únicas para la mayoría de los hogares chilenos que carecen de biblioteca familiar. Los textos analizados y evaluados en este trabajo son los siguientes, (todos ellos en uso en el año 2012):

Gajardo, M.; Guajardo, V.; Biedma, M. (2006-2007). Lenguaje y Comunicación para $7^{\circ}$ Básico. Tercera edición autorizada por el MINEDUC. Editorial Marenostrum (española) impreso en Chile. 192 páginas. 335.001 ejemplares Carreño, R.; Santos, D.; Ávila, N.; Filla, M.; Montes, C. (2010). Lenguaje y Comunicación para $8^{\circ}$ Básico (Guía didáctica del docente y texto del estudiante). Editorial Cal y Canto (chilena). 448 páginas. 7.140 ejemplares Ortúzar, C.; Rodríguez, I. (2002). Lengua Castellana y Comunicación, libro del estudiante para $1^{\circ}$ Medio. Quinta edición, Ministerio de Educación. Editorial Arrayán (editado por R. Donnelly América Latina). 304 páginas. 263.040 ejemplares

Carreño, R.; Santos, D.; Soto, G.; Vera, C. (2001). Lengua Castellana y Comunicación para $2^{\circ}$ Medio. Segunda reimpresión. Ministerio de Educación. Editorial Marenostrum (española), impreso en Chile. 472 páginas. 5.422 ejemplares

Amaro, L.; Caballero, A.; Cabrera, M. (2006). Lengua Castellana y Comunicación, texto para el estudiante para $3^{\circ}$ Medio. Años 2007-2008. Editorial Santillana. 289 páginas. No indica cantidad de ejemplares.

Carreño, R.; Páez, G.; Santos, D.; Soto, G.; Vera, C. (2000). Lengua Castellana y Comunicación, texto del estudiante para $4^{\circ}$ Medio. Segunda edición. Ministerio de Educación. Editorial Marenostrum (española), impreso en Chile. 338 páginas. 140.000 ejemplares

En su mayoría son libros que el Ministerio de Educación le presta a los estudiantes. Son parte de la campaña "Libro de vuelta"; no se pueden rayar, recortar ni escribir. El total de ejemplares circulando alcanza aproximadamente a la suma de un millón. Obviamente que estos textos llegan y se van de las manos de los niños y jóvenes más carenciados cuyos padres no tienen las condiciones económicas para comprarlos e incorporarlos a su biblioteca familiar. 
A partir de esta lista, llama la atención que el Ministerio de Educación, adjudique durante años la licitación de los textos escolares a los profesores de una misma corporación, lo cual se confirma por su afiliación institucional. A juzgar por los textos examinados, son profesores de la Pontificia Universidad Católica de Chile, egresados, trabajando en ella o vinculados a programas de estudios avanzados en el extranjero, los que tienen el monopolio de la confección y edición de estos textos, disputándose las licitaciones de impresión entre la Editorial Española Marenostrum y las filiales Arrayán y Santillana (también de capitales españoles) y Cal y Canto. De 26 profesores participantes en los textos de la muestra más amplia que hemos examinado, 23 pertenecen a la PUC $(85,46 \%)$ y solo $3(11,53 \%)$ pertenecen a otras entidades.

Una evaluación aleatoria a los siete textos de estudio de $7^{\circ}$ Básico a $4^{\circ}$ de Educación Media, de las editoriales ya mencionadas y vigentes desde el 2000, arroja evidencias sobre el grado de incoherencia entre el concepto con que se justifica el rol de los textos escolares y el diseño operante en manos de los estudiantes. Se verifica que hay escasa relación entre el currículo, la declaración de intenciones establecida en la Política Nacional del Libro y la Lectura (2006), los programas y planes de estudio, los Mapas de Progreso y las expectativas de logro.

Las incoherencias que presentan estos textos se verifican en los siguientes aspectos:

$1^{\circ}$ Los criterios editoriales que regulan el diseño de los textos son prácticamente los mismos para todos los niveles según el dictamen curricular de Lectura, Escritura y Comunicación oral. Su referencia son los Objetivos de Aprendizaje (OA) o estándares de contenidos y los Objetivos de Aprendizaje Transversales (OAT), orientados a la meta de desarrollo personal, intelectual, moral y social. En este espacio textual ya no operan los objetivos fundamentales, los contenidos mínimos obligatorios y los objetivos transversales de la derogada LOCE. La matriz común para todos los textos se uniforma a tal grado que de hecho el libro de $8^{\circ}$ Básico es casi igual en contenidos al de $2^{\circ}$ Medio.

$2^{\circ}$ A través de la revisión de los textos, se infiere que los programas de estudio no conciben, de manera explícita, una línea de desarrollo histórico ni contextual en términos de escenificaciones culturales ni periodizaciones de la literatura. La mayoría de las obras literarias citadas o referidas en las unidades didácticas están fragmentadas, omitiéndose además los 
contextos de su publicación. No hay distinciones entre literatura chilena, latinoamericana, general traducida, lusoamericana; se aprecia también una drástica disminución de literatura española.

$3^{\circ}$ El esquema de los contenidos es uniforme para todos los niveles y en unidades que se seccionan en literatura para ejercicios de discusión y debate; argumentación periodística reducida a una laxa y ambigua noción de ensayo, junto a herramientas de comunicación (pragmática) que validan la importancia de los medios de comunicación social y su similitud con el lenguaje de la literatura. La gramática española, en los textos de estudio de Educación Media examinados en esta muestra, se reduce casi a los mismos contenidos y ejercicios destinados a los estudiantes de Educación Básica y Media (prácticamente se repiten las mismas unidades didácticas de $6^{\circ}, 7^{\circ}$ y $8^{\circ}$ Básico en $4^{\circ}$ Medio); se reiteran casi majaderamente y sin diferenciar niveles de complejidad, las mismas unidades: ortografía, partes de la oración gramatical, el signo lingüístico, lexicología (sufijos, infijos, derivación); algunas raíces griegas y latinas, sintaxis (tipos de oraciones, estructura del sujeto y del predicado); gramáticas de textos (cohesión, conectores). Pareciera ser que la meta de estos textos de estudio es capacitar o desarrollar competencias en el exclusivo y funcional ámbito de la comunicación periodística para la formación de un lector mínimo, sin tender o aspirar a la preparación del lector crítico capaz de interpelar y dejarse interpelar estéticamente por lo que lee; se impide que el lector en ciernes desarrolle competencias para captar mensajes y contenidos explícitos contextualizados y que lo habilite para la interpretación de las obras literarias sugeridas. Desde este punto de vista, la reflexión sobre el lenguaje, su uso y aplicación, se orienta básicamente desde la lingüística general, la psicolingüística, la pragmática y las cláusulas retóricas del análisis del discurso, apuntando a facilitar la comprensión de la publicidad, la propaganda, la simbólica comercial y los códigos que interactúan en el mundo moderno. En resumidas cuentas, una visión funcionalista. Un tercio o más del espacio (centímetros cuadrados por página) de los textos están cubiertos por colores, diagramas, mapas conceptuales, muchísimas imágenes, etc. Los repertorios de obras literarias sugeridas, en la mayoría de los casos, están acotados en el concepto de "género literario", sin establecer matrices temporales de contexto, tendencias, situaciones histórico-culturales, anulando la posibilidad de realizar un ejercicio crítico sobre el pasado. Pareciera ser que todos estos aspectos quedan a 
criterio del profesor y obviamente de su bagaje cultural, pero no están explícitamente en los textos de estudio y tampoco en las orientaciones al mismo docente.

Cabe preguntarse quiénes evalúan estos manuales de estudio y luego autorizan su publicación y circulación, incluidas las instrucciones y falacias teóricas que condicionan a los docentes como ocurre al revisar párrafos del Programa de Estudio de $4^{\circ}$ Medio de la Editorial Marenostrum (2000), en la sub-unidad 2.2 sobre temas preferentes y rasgos básicos de la literatura contemporánea. Pareciera ser que la idea de quien formula la teoría es familiarizar a los estudiantes con los temas de la esfera pública y privada de la literatura, sin precisar qué se entiende por una o por la otra. Se afirma que la literatura manifiesta afinidad con el discurso público, aceptándose como válido el ejemplo de "espectacularizar para el público lector, auditor o espectador asuntos y temas" ${ }^{3}$. ¿Qué se quiere decir con espectacularizar temas? ¿Farandulizar la literatura a través de medios masivos que sustituyan el aula y la lectura crítica? ¿Asimilar la literatura al reality televisivo? Visto el fenómeno discursivo desde esta perspectiva, se infiere que la literatura se entiende erróneamente como discurso endogámico, autorreferido, que se toma a sí misma como objeto y tema, incapaz de dialogar con el lector y estimular la reflexión, desde lo propio del pensar literario. Se mantiene la falacia de los formalistas vulgares al creer que el protagonista de los discursos literarios es el lenguaje aislado, sin referentes en la realidad.

Tenemos el derecho a preguntarnos qué experiencias, dominios o competencias en Educación Básica y Media poseen los autores de estos textos de estudio vigentes en las escuelas más pobres; qué visión de país y de educación poseen; qué grado de conocimiento, años de ejercicio profesional, en qué niveles sociales y tipos de escuelas han desarrollado su quehacer habitual. En el texto de estudio de Lengua Castellana y Comunicación de $2^{\circ}$ Medio de la Editorial Marenostrum (2001), se expone la siguiente declaración de lealtad de los autores del texto, con aquello que el Ministerio de Educación considera, en ese momento, reforma educacional: "Hemos puesto especial énfasis en preparar un libro centrado en el desarrollo de la

3 Cf. el Programa de Estudio de Cuarto año Medio Lengua Castellana y Comunicación, 2000, presentado por la Ministra de Educación de ese período, Mariana Aylwin. Páginas 70 y 71 . 
competencia comunicativa y en la expresión personal de la literatura, capaz de dialogar con los nuevos medios informáticos, bibliográficos y didácticos en general, aportados por el Ministerio para el enriquecimiento de los contextos de aprendizaje" ¿Literatura al servicio de la informática y centrado en la "expresión personal" (intimismo, individualismo) de los lectores? Por otra parte, la selección de fragmentos incorporados en algunos textos de estudio son desafortunados para incentivar la lectura y responder a la pregunta recurrente que suelen hacer los adolescentes: - "Profesor, dígame para qué sirve la literatura o esto que estamos estudiando". En el texto de estudio de $1^{\circ}$ Medio de la Editorial Arrayán (2002), además de esfumarse casi al estado de invisibilidad las lecturas mínimas de obras españolas y reduciéndose también al mínimo las obligatorias de latinoamericana, aparece un testimonio de Mario Vargas Llosa, declarado en el Encuentro Latinoamericano de Escritores que se realizó en Chile, en 1969, que revela la falta de prolijidad de los editores para los fines didácticos que seguramente, en sentido contrario, estaban pensando. En su testimonio de juventud, Mario Vargas Llosa se pregunta "¿Para qué sirve la literatura? [...] (-y responde, diciendo-): La verdad es que nosotros no lo sabemos, sino que, racional o irracionalmente, estamos tan indecisos, tan confusos... como cualquiera. Yo creo que esto se debe a la condición misma del escritor y a la naturaleza misma de la literatura" ¿A esta misma pregunta, con la decantación de su experiencia, este Premio Nobel de Literatura de 2010, respondería acaso lo mismo en el presente actual? Es muy probable que no. Si para Mario Vargas Llosa sus obras siguieran siendo una "frustración permanente, sin perspectiva, sin respuesta", estaría autoinvalidando toda una vida y esfuerzo dedicado a la reconocida calidad de su narrativa y a sus interesantes ensayos. Por lo demás, en la línea de reivindicación de las humanidades, creo que no tiene sentido hacernos la pregunta utilitaria sobre para qué sirve la literatura o el arte en general, sino en qué puede contribuir o de qué modo interpela al lector en el contexto de una sociedad mundializada, cautiva de la ideología de la globalización, en

4 Carreño, R; Santos, D; Soto, G; Vera, C., (2001). Lengua Castellana y Comunicación, segunda reimpresión. Santiago, Gobierno de Chile, prohibida su comercialización. Editorial Marenostrum, página 4.

Vargas Llosa, Mario (1969): “¿Para qué sirve la literatura?”, páginas 254 y 255, en Lengua Castellana y Comunicación de $1^{\circ}$ Medio, 2002, quinta edición, de 263.040 ejemplares, editado por el Ministerio de Educación, de la periodista Carmen Ortúzar y del profesor Ignacio Rodríguez. 
que la humanidad se debate entre el desengaño y la indignación. Vista en su posibilidad como discurso imprescindible para una nueva estética social, la literatura deja de ser un ritual compensatorio de la impotencia del hombre actual, contribuyendo con creces, en nuestro mundo, a modificar las cegueras de la época contemporánea. Literatura como resistencia ética y salvaguarda estética, desde y en la palabra, toma de conciencia sobre la condición del hombre de todas las épocas, posibilidad de luchar contra el olvido y evitar que nos perdamos en la simultaneidad de los mensajes que subyacen en la selva de las imágenes de la publicidad y de la propaganda.

\section{OTRAS EVIDENCIAS DEL OCULTAMIENTO CURRICULAR Y RESTITUCIÓN DE LAS HUMANIDADES}

El desacople estructural a que nos hemos referido, y que se patentiza en los textos de estudio, debe ser superado a la hora de iniciar un diálogo y un intercambio de ideas para darle coherencia a propuestas sobre una educación encarnada en las humanidades y en las ciencias, cuyo sistema y opciones políticas, económicas, culturales y técnicas, deben ser revisadas y pensadas para cambios de fondo en la perspectiva de restituir una educación integral y humanizadora. Se requerirá de una actitud honesta y crítica sobre los efectos de una educación excesivamente pragmática, mecanicista y conductista que solo se propone calificar y aportar una formación instrumental para el empleo y la supervivencia económica. Debemos reconocer que las intervenciones realizadas a la educación chilena, desde 1973 en adelante, han sido mercantiles en detrimento de las más elementales consideraciones antropológicas y humanistas. En otros casos, los hechos han refutado las incongruencias de la Propuesta Curricular de 1977, defendida por Felipe Allende y Mabel Condemarín ${ }^{6}$, la que entre otras aspiraciones justificaba sin más la eliminación de la Pedagogía en Castellano y aceptaban sustituirla por

\footnotetext{
Recomiendo al lector confrontar la monografía De la asignatura de castellano al área del lenguaje. Lengua Castellana y Comunicación en la Educación Media (1997), de Felipe Allende y Mabel Condemarín. Santiago: Editorial Dolmen, 244 páginas. Hoy en día, ante la crisis del modelo, resulta interesante releer esta obra tan contradictoria e influyente en la ideología dominante de la época. Ambos autores demuestran que se embarcaron en un formalismo teórico educativo, técnico-lingüístico, positivista y erudito, sin visión crítica y sin reflexionar sobre el rol de las humanidades. Diferente, en cambio, e instrumentalmente
} 
un régimen curricular que en adelante se podía cubrir-según ellos-con los nuevos planes y programas de Comunicación y Lenguaje. La propuesta en los años que vienen debe acoplar armónicamente todas las variables de un sistema que privilegie las humanidades para otorgar una formación integral mirando no al mercado sino al ser humano en su dimensión crítica y creativa. La nula incidencia de las humanidades se evidencia en los resultados negativos que el sistema ha acumulado hasta la fecha. El informe PISA 2009 señala que uno de cada tres estudiantes chilenos no entiende lo que lee y solo el $1 \%$ es capaz de reflexionar sobre lo leído; en la prueba PISA del mismo año, los estudiantes chilenos obtuvieron un promedio de 439 puntos, en cambio el promedio OCDE fue 497. En 2006, año de brusca expansión de la cobertura que constituyó el grupo más grande que rindió, en ese entonces, la Prueba de Selección Universitaria (PSU), con 211.251 estudiantes, los resultados fueron los siguientes: 6.927 postulantes obtuvieron más de 700 puntos en la prueba de lenguaje $(3,27 \%)$. 7.040 superaron la barrera de los 700 en el test de matemáticas $(3,33 \%)$ y solo 200 jóvenes alcanzaron 850 puntos o más (0,09\%). El 93,29\% rindió menos de 600 puntos.

Quienes trabajamos en programas de pedagogía, día a día comprobamos que intentar formar pedagogos de calidad que ingresan bajo la línea de los 600 puntos es una tarea escasamente productiva en términos de cambiar radicalmente sus hábitos y mejorar su capital cultural, a no ser que las acciones tutoriales alarguen el tiempo de formación sobre la base de un currículo adecuado a los fines de nivelación hacia arriba. Los cursos de primer año de pedagogía, con ingresos entre los 500 y los 580 puntos, en realidad son la prolongación de la Enseñanza Media y poco se puede avanzar en un "quinto medio", sin planes especiales de recuperación, más aún cuando las universidades privadas no están dispuestas a proporcionar más tiempo e inyectar más recursos económicos a la formación pedagógica. Por el contrario, la tentación mercantil del sistema es acortar las carreras, reducir el tiempo de formación y, por ende, reducir el número de las asignaturas del currículo. Al respecto vale la pena señalar que desde que se implementó el Proyecto de Formación Inicial Docente a partir del 2000, la propuesta es acortar la Pedagogía en Castellano (de 10 a 8 semestres), por considerar que el currículo enciclopedista era inconducente en relación a los parámetros de la OCDE.

adecuado para la didáctica, es el libro de los mismos autores La lectura: teoría, evaluación y desarrollo. Editorial Andrés Bello, 1990, 315 páginas. 
De 70 asignaturas, los planes de formación actual se reducen a un promedio de 50, conservando los mismos cinco años. Al reducirse a solo 7 semestres efectivos de actividades lectivas o cuatro años incluida la práctica profesional de dieciséis semanas, las asignaturas se deberían rebajar a menos de 40; es decir, en casi un $50 \%$ en relación con lo que en Chile se exigía para obtener el título de Profesor de Estado. Felizmente, no todos los Pedagógicos han caído o caerán en esta ceguera. La Facultad de Humanidades de la USACH, por ejemplo, mantiene la carrera de Pedagogía en Castellano con ingresos sobre los 620 puntos, con una duración de cinco años y con un currículo de 62 cátedras, epistémicamente bien equilibrado de acuerdo con los escasos recursos de una universidad del Estado ${ }^{7}$. Quienes tenemos la experiencia de trabajar en universidades públicas y en privadas que reciben estudiantes con menos de 600 puntos, conocemos fehacientemente la diferencia que hay entre los egresados de una y otra. Por cierto, en las privadas hay estudiantes excepcionales y claramente se destacan los que más han leído y reflexionado en torno a las ciencias sociales y al campo general de las humanidades y las artes durante su formación básica y media.

\section{CONCLUSIONES}

Además de aceptar que el desafío político y económico de fondo es la equidad como base de la calidad para una educación (igualitaria en oportunidades), producto de un cambio estructural del modelo, y tal como lo hemos demostrado en las políticas educacionales promovidas en los últimos cuarenta años, se hace evidente un menoscabo de las humanidades, especialmente en la asignatura de Castellano y en los textos de estudio licitados por el Ministerio. Cabe preguntarse cómo remediar, en el futuro, esta situación; ¿qué ofrecer para superar esta crisis? y ¿cómo formar a quienes hoy sueñan con realizarse a

7 No obstante, los petitorios estudiantiles elaborados después de "tomas" y largos paros de protestas estudiantiles (2011 a 2013), los jóvenes hacen serías y razonadas críticas a las debilidades curriculares: debilidades en el clima de trabajo en aula, exceso de lingüística, ausencia de dramaturgia y ejercicios de expresión oral y de comprensión lectora, prácticas tardías, falta de vínculos entre educación y literatura y casi nulas expresiones de vida en comunidad académica entre profesores y estudiantes. Como solución plantean la revisión de los contenidos mínimos de formación y la revisión del perfil de egreso en claustros con la participación de académicos junto a ellos. 
través de su vocación de maestros y a quienes se están educando, en otras disciplinas afines, para aprender y enseñar a leer literatura.

Planteo que habría que comenzar proponiendo los siguientes objetivos, sin jerarquizarlos ni restar posibilidades de mejora de acuerdo a la teoría y a la práctica pedagógica:

$1^{\circ}$ Enseñar a leer, aceptando que enseñar a leer es enseñar a pensar, hábito intelectual para el desarrollo de la conciencia crítica. No existe didáctica de la literatura. Aprender a leer es más que enseñar literatura. Corregir el error de algunos didactólogos que creen que las artes y la literatura se leen y se enseñan como la aritmética o la biología.

$2^{\circ}$ Enseñar a leer literatura demanda un esfuerzo adicional por la condición estética de la obra literaria. A través de este ejercicio, cultivar la capacidad crítica y autónoma del pensar literario. Grínor Rojo critica a aquel sector de la academia universitaria que se dedica a hacer una "ciencia de la literatura aséptica, higienizada, objetiva y neutral". No más cientificismo literario o crítica basada en la lingüística. Hay que saber responder a la pregunta sobre cuál es el objeto de estudio que emerge de la lectura razonada. Leer y estudiar literatura es atender, pensar, comprender, disfrutar e interpretar lo que las obras dicen; saber distinguir cómo nos hablan sobre la condición y las veleidades humanas, la sociedad y el contexto histórico, lo que ayuda a diferenciar los modos de sentir, luchar, imaginar, nacer, vivir, agonizar y morir de la humanidad.

$3^{\circ}$ Enseñar a leer libros clásicos: hay que recuperar su importancia como capital cultural, máximo de posibilidades que la naturaleza nos ha dejado como herencia simbólica del pueblo en que se vive y actúa. Descubrir la gracia y capacidad de las obras clásicas en su forma de seguir hablando e interpelando al hombre del presente, sabiendo que han sido escritas en otro tiempo y desde otros lugares de enunciación.

$4^{\circ}$ Defender la cultura de las humanidades como cultura crítica y creativa, en contra de una visión tecnocrática, utilitaria e instrumental de las mismas. Nuevamente habrá que resituar a las humanidades y la contribución de los humanistas para retomar el cauce de una cultura planetaria que cada día se resiste más a la degradación de la vida humana y no humana.

$5^{\circ}$ Acabar con la propuesta de 1977, la fusión y desperdicio de los planes y programas de comunicación y lenguaje con los de gramática y literatura, 
siempre en detrimento de esta últimas. La literatura es "Arte Verbal", es estética y no comunicación instrumental. Terminar con esta castrante, ignorante y utilitaria aberración. Los lingüistas confunden el discurso literario con el texto narrativo. El primero es literatura, el segundo no lo es. Su capacidad comunicativa, intersubjetiva entre personas, más que intercambio de mensajes, es una exigencia por la dignidad y la recuperación de la libertad frente a las estructuras sociales que vapulean, niegan, manipulan; se trata de superar al hombre unidimensional atrapado en la jaula del pensamiento único.

$6^{\circ}$ Recuperar el rol del profesor como mediador efectivo, orientador y tutor de la lectura; eximirlo de su rol evaluador de la comunicación perdiendo su tiempo en transmitir una cuasi disciplina de filosofía del lenguaje (argumentación) que solo contribuye al desencanto y aburrimiento de los lectores en ciernes. El profesor que no genera el hábito y el entusiasmo por la lectura no califica como maestro. Debe ser un lector incesante para que seleccione bien lo que ofrece a sus estudiantes. Hay muchos modos de acercarse a la literatura; desde la experiencia personal como sujeto social, contexto histórico y disyuntivas políticas, géneros literarios, temas, estilos, estructuras, perspectivas de recepción, horizontes hermenéuticos, etc.

¿Cuál es la idea de lo humano en el desplazamiento de las humanidades producido bajo el amparo del modelo neoliberal en educación? Expertos y eruditos del mercado versus académicos, investigadores y profesores, nos formulamos preguntas divergentes, pero nadie puede desconocer que el humanismo siempre es plural, democrático, popular, reflexivo, abierto a las posibilidades de redención de los derechos fundamentales. Hay que impedir que siga imponiéndose el individualismo y el pensamiento instrumental en función de una vida reducida solo a la subsistencia o al éxito económico. La presencia de las humanidades tiene mucho que aportar en este proceso de recuperación. 